\title{
Developing and Establishing the Psychometric Properties of an Ethos towards Wellness Questionnaire (EtWeQ)
}

\author{
Bengt Fridlund ${ }^{1,2}$, Amir Baigi ${ }^{2}$ \\ ${ }^{1}$ School of Health Sciences, Jönköping University, Jönköping, Sweden \\ ${ }^{2}$ The Sahlgrenska Academy, Göteborg University, Göteborg, Sweden \\ Email: ${ }^{*}$ bengt.fridlund@hhj.hj.se
}

Received 29 April 2014; revised 30 May 2014; accepted 13 June 2014

Copyright (C) 2014 by authors and Scientific Research Publishing Inc.

This work is licensed under the Creative Commons Attribution International License (CC BY).

http://creativecommons.org/licenses/by/4.0/

(c) (i) Open Access

\begin{abstract}
Aim: Validated instruments exist measuring parts of personal health, ill-health and lifestyle, but there are few, if any, instruments "grasping the big picture" of wellness and ethos. Accordingly the aim was to develop and establish the psychometric properties of a 74-item Ethos towards Wellness Questionnaire (EtWeQ) with regards to content and construct validity, as well as homogeneity and stability reliability. Methods: A questionnaire based on a methodological and developmental design was sent out twice with a four week gap between, on 221 healthy middle-aged participants in four steps: item generating, content validating, statistical analyzing and establishing the final questionnaire. Results: The substantial base, consisting of content validity resulted in, besides basic characteristics, six well-defined and sufficient indexes comprising of; two health indexes (healthiness and ill-healthiness), three life context indexes (work, family, spare time), and one brief comprehensive index (ethos). The three life context as well as the ethos indexes at an ordinal scale level, identified overall satisfactory communalities of $>0.30$, factor loadings $>0.30$, and factor total variance $>\mathbf{5 0} \%$ with regard to construct validity. The homogeneity reliability, in terms of Cronbach's alpha coefficient $>0.70$, at both occasions with a four week gap between, as well as the stability reliability in terms of intraclass correlation coefficient $>\mathbf{0 . 7 0}$, were also considered satisfactory in the same indexes. Conclusions: This newly developed, and likely the only questionnaire focusing on "grasping the big human picture", was based on both a philosophical reasoning and empirical recommendations of wellness, is shown to be a valid and reliable measurement in screening or in follow-up of healthy people's wellness and ethos.
\end{abstract}

\section{Keywords}

Ethos, Healthy Factors, Holistic, Psychometrics, Wellness

\footnotetext{
${ }^{*}$ Corresponding author.
}

How to cite this paper: Fridlund, B. and Baigi, A. (2014) Developing and Establishing the Psychometric Properties of an Ethos towards Wellness Questionnaire (EtWeQ). Open Journal of Nursing, 4, 538-547. 


\section{Introduction}

The concept of wellness is a multidimensional state of being, describing the existence of health in an individual as exemplified by sense of wellbeing and quality of life [1] [2]. The previous definition of health held the perspective that health was concerned with illness and the body was considered in negative terms of isolated parts, for example: a biomedical condition, while the wellness concept reflects the positive terms of all parts of the individual, i.e. a holistic attitude also including a more subjective and emotional condition [3]. Wellness is understood as more than just the absence of negative elements (e.g. illness and disease), but also the presence of positive elements (e.g. physical health and happiness). So by linking the concepts of wellness and salutogenesis including a sense of coherence (SOC) [4] [5], together it is possible to concretize the individual's experience to understand, manage and see the meaning of life. Such a holistic perspective raises the awareness of an individual's ethos comprising the interaction with the whole environment intertwining with family, work, and spare time. This may affect the individual's wellness for good or bad. This interaction creates a complex set of symbols in the individual, i.e. motives, attitudes, values, knowledge, experience, which enable or not enable a relevant context or meaning of life [6] [7]. Interaction is also a process in which the individual exists, is amenable and involves and creates a role identity, such as: responds to behavior and expressions from society mainly family members, relatives, friends, and work colleagues. The meaning or influence on wellness of such an encounter is dependent on what needs the individual has and on what demands these cause and what resources the individual mobilizes or gets support from others [4] [8] in maintaining or restoring wellness. Together these predict the motivation towards the wellness of the individual. This may be directed through the SOC's components; comprehensiveness, manageability and meaningfulness to tackle the task towards wellness, for example commencing to exercise and the pros and cons of doing this, hopefully having a body that works, obtaining positive interactions with other people, sleeping better, becoming more stress resistant, and why it is worth an investment. Motivation is an individual's driving force to achieve their goal of wellness in order to minimize feeling bad and to maximize feeling good [9]. The motivation is conditional on the individual's needs or inner motives which have to be in balance and harmony [10]. When these inner motives are met, the individual's experience is to have control over and feel satisfaction in life, with the individual's ethos doing well. No individual can handle the task towards wellness alone, so family, co-workers, managers and friends are resources, often become the social support system [8] facilitating, but also, at times hampering the individual's SOC. European examples how the work and family life affect the individual's wellness_-positively or negatively_on the basis of job demands, personal resources and support from co-workers, managers and family are fairly established today, but these few ones show role stress at work and family as a major threat towards health and wellness [11]-[17]. There are no documented wellness interventions comprising of an ethos perspective. A decisive cause is the absence of instruments measuring the adult individual's ethos based on the multidimensional wellness state of being. However there are a number of validated instruments measuring parts of personal health, ill-health and lifestyle (e.g. diet, exercise, smoking, stress). However, there are no reported instrument for "grasping the big picture" of wellness and ethos, except possibly the Personal Wellness Profile (PWP) questionnaire [18]. Accordingly the aim of this study was to develop and establish the psychometric properties of the Ethos towards Wellness Questionnaire (EtWeQ) with regard to content and construct validity as well as homogeneity and stability reliability.

\section{Material and Method}

\subsection{Design}

The study utilized a methodological and developmental design with approval from the Swedish Information Act. It was carried out in four steps: item generating, content validating, statistical analyzing and establishing the final questionnaire.

\subsection{Development and Establishment of the Ethos towards Wellness Questionnaire (EtWeQ)}

\section{Step 1: Item generating}

Items were constructed and related to well-known empirical studies and existing health theories [2] [5] [8]-

[10]. This was undertaken by the first author, a social scientist and registered nurse with extensive experience in 
both health promotion and disease prevention issues. This was beneficial as it assisted in catching an individual's outlook, for example; examining the ethos in order to see and understand the individual's wholeness [3] on the basis of a healthy approach towards reaching wellness [1]. It should be noted that an individual should be understood and operationalized by his/her features and habits intertwining in the context of family, work, and spare time life, where both healthy (constituents: good sleep, positive stress, good relationships) and unhealthy items (constituents: poor sleep, negative stress, poor relationships, smoking, sedentary life) exist. These may affect the individual towards wellness, ill-health or illness. The first author, together with a public health epidemiologist, a communication researcher, an occupational therapist and a school health nurse, all with many years of both clinical and theoretical skill in health and wellness issues as well as instrument development developed a 70-item questionnaire comprehending the individual's wholeness, formed of life contexts and the comprehensive ethos. Accordingly the initial EtWeQ comprised of seven health and wellness modules: the 7-item Individual Basic Characteristics, 15-item Healthiness Index, 12-item Unhealthiness Index, 9-item Work Life Context Index, 9-item Family Life Context Index, 9-item Spare Time Life Context Index and the 9-item comprehensive Ethos Brief Index.

\section{Step 2: Content validating}

After construction of the first draft of the questionnaire, assessing of content verification, including face validity and think aloud sessions took place [19]. Face validity was scrutinized by 15 employees of a wellness company and again further by 12 interdisciplinary health professionals. These individuals evaluated, reflected and gave verbal and written feedback of the draft questionnaire. The questionnaire was also scrutinized during three focus group seminars based on think aloud protocols [20]. Face validity and aloud assessment led to the adjustment of some constituents and changes to the language. In addition to this, five constituents were added and one was extracted with regard to the Healthiness as well as the Unhealthiness indexes. No change in regard to the four Life Context/Ethos indexes was found to be needed. This resulted in a total of 74 constituents before data analysis (see Figure 1).

\section{Step 3: Statistical analyzing}

Testing for theory validity (construct validity) and reliability (homogeneity and repeatability stability) was carried out in SPSS 20.0 (SPSS Inc., Chicago, IL, USA). Construct validity was assessed with item construct validity with explorative factor analysis (principal analysis through Varimax rotation) and Kaiser Normalization, in order to reduce number of items and to emphasize apparent factors. Also Bartlett's test of Sphericity $(P<0.05)$ and the Kaiser-Meyer-Olkin Measure of sampling adequacy $(>0.60)$ were used in fulfilling this factor analysis. The criterion for factor extraction was an Eigenvalaue $>1$, including items with communalities $>0.30$ and factor loadings $>0.30$, including a total variance of $>50 \%$ [21]. Homogeneity reliability was tested using Cronbach's alpha coefficient $(>0.70)$ [21]. Repeatability stability reliability was tested with intraclass correlation coefficient (ICC > 0.70). The completed questionnaire, as presented in Figure 1, was piloted on 109 healthy individuals with satisfying results [19].

\section{Step 4: Establishing the final questionnaire}

The Individual Basic Characteristics embodying the individual's socio-demographic background and the Healthiness as well as the Unhealthiness Indexes embodying the individual's healthy and unhealthy features and habits, were responded to with Yes/No or with a figure (how much, how often) response. The three life context indexes: Work Life Context Index, Family Life Context Index and Spare Time Life Context Index as well as the comprehensive Ethos Brief Index were all answered on a scale from 0 (very bad) to 10 (very good). All indexes were weighted based on and adapted to recommendations or suggestions from national guidelines or authorities: the Healthiness Index, a positive healthy outcome in full brings two points per item, one point for following but not strictly. For example around $10 \%-15 \%$ above/below the stipulated recommendations/suggestions and zero point, if not at all following the recommendations/suggestions (e.g. sleeping 6 - 8 hours $=2$ points; sleeping 5 6 or 9 - 10 hours 1 point; sleeping $<5$ and $>10$ hours $=0$ point). Furthermore, the Unhealthiness Index, if absence of any unhealthiness features or following the national recommendations/suggestions bring one point per constituent. For example, no known cardiovascular disease; experiencing negative stress (not at all, to some times a week) and zero point, if having illness, ill-health or vicious life habits (e.g. experiencing negative stress several times a week, to on daily basis). Finally, the three Life Context Indexes as well as the comprehensive Ethos Brief Index, were weighted on the same basis, that being; reaching $80 \%$ or more per index implies two points, between $79 \%$ - $60 \%$ implies one point, and $59 \%$ or less implies zero point.

The scores were summarized as total sums making min-max points of 0 - 34 for the Healthiness Index (17 
Individual basic characteristics

Highest level of education

Marital status - Children living at home

Normal working hours/w

Total working time/w

Total sick leave/m

Total healthy workdays/m

\section{Healthiness Index}

Pulse

Blood pressure

Height

Weight

BMI

Exercise intake

Sleep intake

Breakfast intake

Vegetable-Fruit-Berry intake

Fish-Seafood intake

Red wine intake

Engagement in relationships

Engagements in the workplace

Engagement in the family

Engagement in friends and relatives

Engagement in leisure-free time

Control of life

\section{Unhealthiness Index}

Heart-vascular disease

Psychiatric/mental disorder

Diabetes

Hyperlipidemia

Asthma-Allergy

Chronic pain-Aches

Psychological troubles

Social troubles

Poor work relationships

Poor family relationships

Alcoholic habits

Smoking habits

Snuffing-Chewing tobacco habits

Bad stress habits

\section{Work Life Context Index}

My workplace cares about me

I adapt to my workplace needs and demands

I feel balance and harmony in my work

I thrive with my work colleagues

I thrive with my managers

I thrive in/with my work role

I feel meaningful at/for my workplace

I contribute to the development of my workplace

I feel appreciated and receive the salary and benefits that I deserve

\section{Family Life Context Index}

My family cares about me

I adapt to my family's needs and demands

I feel balance and harmony in my family

I thrive with my family

I thrive with my housing

I thrive in/with my family role

I feel meaningful in/for my family

I contribute to the development of my family

I feel appreciated and receive love and friendship in return for the contributions that I make 


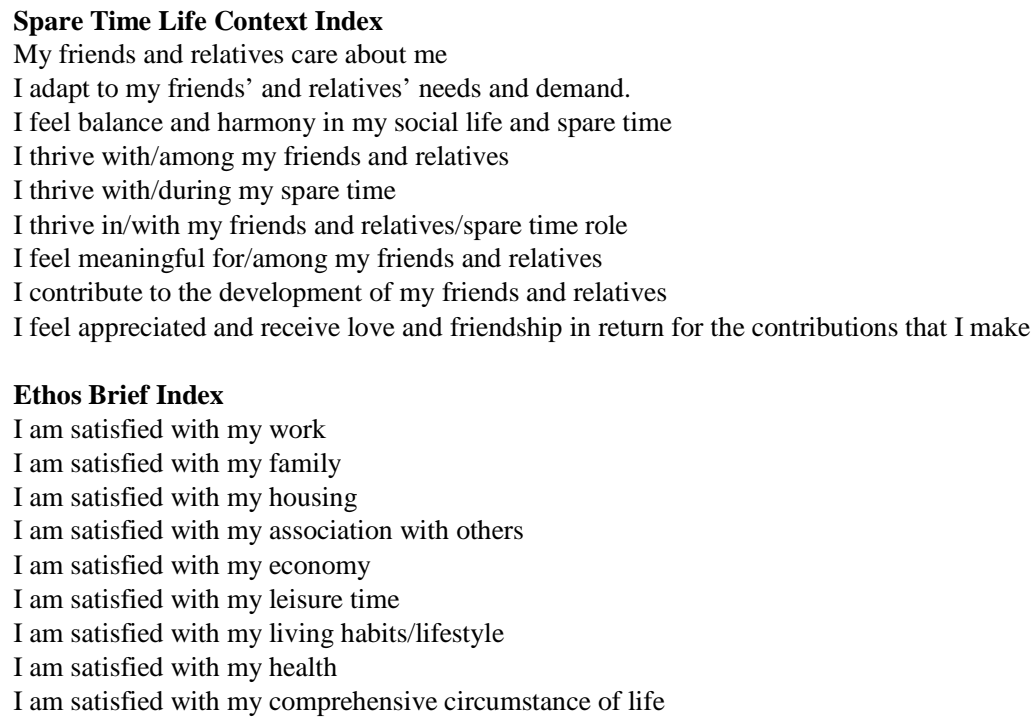

Figure 1. The Ethos towards Wellness Questionnaire (EtWeQ) comprising of individual characteristics, the two Healthiness and Unhealthiness Indexes, the three Life Context Indexes and the comprehensive Ethos Brief Index.

constituents) and 0 - 14 points for the Unhealthiness Index (14 constituents). Cut-off values were set down as; excellent ( $80 \%$ or more), good $(60 \%-79 \%)$, and not so good $(<60 \%)$. The three life context indexes (9 constituents each) and comprising of the individual's emotional, existential, intellectual and social wellness, were also summarized as total sums making min-max points of 0 - 90 for each context index. Identically, these cut-off values were set down as; excellent (80\% or more), good (60\% - 79\%), and not so good (<60\%). Also, the comprehensive Ethos Brief Index (9 constituents) comprising of the satisfaction with most life contexts, for example; the ethos (economy, family, housing, life habits, social life, spare time, work), were also processed in the same manner.

\subsection{Participants, Sampling and Setting}

Participants were collected from a consecutive sample of people $(\mathrm{N}=6005)$ who were participating in a Swedish yearly nationwide fitness implementation program [22] on voluntary basis. The implementation focus was on the practicing of sound exercise, but also on the recommendations and suggestions regarding diet and social habits according to national medical and behavioral guidelines. In order to make a distinct factor analysis, at least 100 participants were stipulated to capture those 10 individuals per item (constituent) as recommended [21] The first 220 participants who responded to the questionnaire twice-both before and after the implementation and within four weeks - were collected for analyses. The distribution with regard to sex, age and the highest level of education were; $85 \%$ women, mean age 45.7: SD $=10.6$, and 42\% with university level education, respectively.

\section{Results}

\subsection{Construct Validity}

The process of reducing the number of constituents was conceptually, as well as statistically, scrutinized with regard to the meaning of each constituent as well its relation to each index, see Table 1 . The number of constituents was accordingly both added and reduced from 70 to 74 to increase the content and readability of the Healthiness and Unhealthiness Indexes. With regard to the four Life Context/Ethos Brief indexes, no changes were carried out even if the statistical process of scrutinizing showed such possibilities concerning some low figures in communalities (two constituents: Work Life Context Index; 0.29 and Family Life Context Index; 0.15). However, with the overall theoretical and conceptual analogy and affinity in mind, it was decided to keep 
Table 1. Construct validity (explorative factor analysis with principle component analysis and Varimax rotation with Kaiser Normalization), $\mathrm{n}=221$.

\begin{tabular}{|c|c|c|c|c|c|c|}
\hline Life Context/Comprehensive Index including constituents & $\begin{array}{c}\text { Total } \\
\text { variance \% }\end{array}$ & Communalities & Work & Family & Spare time & Ethos \\
\hline Work & 54 & & & & & \\
\hline My workplace cares about me & & 0.65 & 0.81 & & & \\
\hline I adapt to my workplace's needs and demands & & 0.29 & 0.54 & & & \\
\hline I feel balance and harmony in my work & & 0.50 & 0.71 & & & \\
\hline I thrive with my work colleagues & & 0.44 & 0.66 & & & \\
\hline I thrive with my managers & & 0.55 & 0.74 & & & \\
\hline I thrive in/with my work role & & 0.64 & 0.80 & & & \\
\hline I feel meaningful at/for my workplace & & 0.73 & 0.85 & & & \\
\hline I contribute to the development of my workplace & & 0.54 & 0.73 & & & \\
\hline I feel appreciated and receive the salary and benefits that I deserve & & 0.49 & 0.70 & & & \\
\hline Family & 60 & & & & & \\
\hline My family cares about m. & & 0.64 & & 0.80 & & \\
\hline I adapt to my family's needs and demands & & 0.15 & & 0.38 & & \\
\hline I feel balance and harmony in my family & & 0.75 & & 0.87 & & \\
\hline I thrive with my family & & 0.72 & & 0.85 & & \\
\hline I thrive with my housing & & 0.33 & & 0.58 & & \\
\hline I thrive in/with my family role & & 0.77 & & 0.88 & & \\
\hline I feel meaningful in/for my family & & 0.78 & & 0.88 & & \\
\hline I contribute to the development of my family & & 0.60 & & 0.78 & & \\
\hline $\begin{array}{l}\text { I feel appreciated and receive love and friendship in return for the } \\
\text { contributions that I make }\end{array}$ & & 0.71 & & 0.84 & & \\
\hline Spare time & 73 & & & & & \\
\hline My friends and relatives care about me. & & 0.74 & & & 0.86 & \\
\hline I adapt to my friends' and relatives' needs and demand. & & 0.50 & & & 0.70 & \\
\hline I feel balance and harmony in my social life and spare time & & 0.79 & & & 0.89 & \\
\hline I thrive with/among my friends and relatives & & 0.79 & & & 0.89 & \\
\hline I thrive with/during my spare time & & 0.60 & & & 0.77 & \\
\hline I thrive in/with my friends and relatives/spare time role & & 0.79 & & & 0.89 & \\
\hline I feel meaningful for/among my friends and relatives & & 0.85 & & & 0.92 & \\
\hline I contribute to the development of my friends and relatives & & 0.68 & & & 0.83 & \\
\hline $\begin{array}{l}\text { I feel appreciated and receive love and friendship in return for the } \\
\text { contributions that I make }\end{array}$ & & 0.81 & & & 0.90 & \\
\hline Ethos & 55 & & & & & \\
\hline I am satisfied with my work & & 0.39 & & & & 0.62 \\
\hline I am satisfied with my family & & 0.57 & & & & 0.76 \\
\hline I am satisfied with my housing & & 0.52 & & & & 0.72 \\
\hline I am satisfied with my association with others & & 0.51 & & & & 0.71 \\
\hline I am satisfied with my economy & & 0.38 & & & & 0.61 \\
\hline I am satisfied with my leisure time & & 0.68 & & & & 0.82 \\
\hline I am satisfied with my living habits/lifestyle & & 0.65 & & & & 0.81 \\
\hline I am satisfied with my health & & 0.50 & & & & 0.70 \\
\hline I am satisfied with my comprehensive circumstance of life & & 0.78 & & & & 0.88 \\
\hline
\end{tabular}


the constituents and indexes as the statistical figures altogether were acceptable; every Life Context/Ethos Brief Index loaded on one single factor with an Eigenvalue $>1$ with total variance percent between $54 \%-73 \%$ including factor loadings between 0.54 - 0.85: Work Life Context Index, 0.38 - 0.88: Family Life Context Index, 0.70 - 0.92: Spare Time Life Context Index, and 0.61 - 0.88: Ethos Brief Index.

\subsection{Homogeneity and Stability Reliability}

When scrutinizing the seven indexes concerning reliableness, solvency and dependability, these together with their constituents, were considered feasible and understandable as well readable and easy to fill in repeatedly, see Table 2. The homogeneity reliability, in terms of Cronbach's alpha coefficient, were considered good in all four Life Context/Ethos Brief Indexes at both occasions/tests with four weeks between; Work Life Context Index: 0.89 and 0.91, Family Life Context Index: 0.91 and 0.93, Spare Time Life Context Index: 0.95 - 0.96 and comprehensive Ethos Brief Index: 0.89 and 0.90 . With regard to stability reliability in terms of ICC, two constituents dropped somewhat beyond the stipulated level of 0.70: 0.61 in Family Life Context Index and 0.66 in Spare Time Life Context Index. However, with regard to the similar conceptual and theoretical reasoning of validity it was decided to retain them as they contributed in the whole to both of each factor, as the figures were not critical. Accordingly, the ICC figures were considered acceptable or good showing values between 0.75 0.91: Work Life Context Index, 0.61 - 0.87: Family Life Context Index, 0.66 - 0.83: Spare Time Life Context Index, and 0.79 - 0.89: comprehensive Ethos Brief Index.

\section{Discussion}

The development of this questionnaire had its ground in the lack of a well-established, as well as psychometric tested instruments. The questionnaire was designed to measure wellness, such as; strengthening the individual's emotional dimension, but also the distinctive and holistic spirit of the individual, for example; the ethos of how (s)he understands her/his ethos as a wholesome person [1]. Accordingly, the questionnaire has its ontology in humanism and the epistemology in the emic world. This is comprised of how the individual thinks, perceives the world, the rules for behavior, what has meaning, and how to imagine and explain things [23]. According to given psychometric explanations as well as philosophical reasoning (wellness and salutogenesis), only one instrument has been found so far, but this 75-item PWP questionnaire has no philosophical roots, but is grounded on national medical and behavioral guidelines [18]. Further, it has only been tested once for psychometric properties in a small sample of African American college women [18], while this EtWeQ questionnaire is the first attempt to measure wellness and ethos on both sexes built on theoretical (philosophical) as well as empirical (national authorities' guidelines and suggestions) data in a healthy middle-aged Swedish population. With regard to validity, a profound content validity was performed by engaging multi-professional experts, as well as a pilot population giving their views of both context and readability (reading comprehension and answering options) and concerning constituents as well as index. For example, in its part, and in its comprehensiveness starting from both a philosophical (wellness and salutogenesis) and empirical ground (national medical and behavioral guidelines and suggestions). This substantial base resulted in six well defined and sufficient indexes comprising of two health indexes (healthiness and unhealthiness), three life context indexes (work, family, spare time) and one brief comprehensive index (ethos). These last four indexes, at an ordinal scale level which therefore could be subjected to factor analyses, showed good to excellent communalities ( $>0.30)$, factor loadings $(>0.30)$ and factors $(>50 \%)$ with regard to construct validity [21], with a minor limitation in one constituent each in the commonalities of Work Life Context (0.29) and Family Life Context (0.15) indexes. This was found to be acceptable when developing and establishing a new instrument. As validity and reliability stick together, it is very likely that the reliability figures also should be sufficient. Accordingly, both the homogeneity and stability showed good to excellent relationships. On both occasions, with four weeks between, the homogeneity was excellent [21] and logically the figures were also somewhat higher at the second 4-week measurement. With regard to 4-week stability, the figures were also good to excellent. However, two items, one each in the Family Life Context (0.61) and Spare Time Life Context (0.66) indexes, showed a moderate to good relationship (0.50 0.75) according to Cohen et al. [24].

\section{Limitations}

The selection of the population is always crucial. In this case it was a self-selected group of middle-aged partic- 
Table 2. Homogeneity (Cronbach’s alpha coefficient) and stability (Intraclass Correlation Coefficient [ICC]) reliability, $\mathrm{n}=$ 221.

\begin{tabular}{|c|c|c|c|c|}
\hline \multirow{2}{*}{ Life Context/Comprehensive Index including constituents } & \multirow{2}{*}{ ICC } & \multirow{2}{*}{$95 \% \mathrm{CI}$} & \multicolumn{2}{|c|}{ Cronbach's alpha coefficient } \\
\hline & & & $1^{\text {st }}$ occasion & $2^{\text {nd }}$ occasion \\
\hline Work & & & 0.89 & 0.91 \\
\hline My workplace cares about me & 0.87 & $0.82-0.90$ & & \\
\hline I adapt to my workplace’s needs and demands & 0.76 & $0.68-0.81$ & & \\
\hline I feel balance and harmony in my work & 0.79 & $0.73-0.84$ & & \\
\hline I thrive with my work colleagues & 0.86 & $0.81-0.89$ & & \\
\hline I thrive with my managers & 0.91 & $0.88-0.93$ & & \\
\hline I thrive in/with my work role & 0.84 & $0.79-0.88$ & & \\
\hline I feel meaningful at/for my workplace & 0.79 & $0.72-0.84$ & & \\
\hline I contribute to the development of my workplace & 0.75 & $0.67-0.81$ & & \\
\hline I feel appreciated and receive the salary and benefits that I deserve & 0.83 & $0.78-0.87$ & & \\
\hline Family & & & 0.91 & 0.93 \\
\hline My family cares about me & 0.85 & $0.81-0.89$ & & \\
\hline I adapt to my family's needs and demands & 0.61 & $0.49-0.70$ & & \\
\hline I feel balance and harmony in my family & 0.85 & $0.80-0.88$ & & \\
\hline I thrive with my family & 0.87 & $0.84-0.90$ & & \\
\hline I thrive with my housing & 0.87 & $0.83-0.90$ & & \\
\hline I thrive in/with my family role & 0.87 & $0.83-0.90$ & & \\
\hline I feel meaningful in/for my family & 0.86 & $0.82-0.89$ & & \\
\hline I contribute to the development of my family & 0.80 & $0.73-0.84$ & & \\
\hline $\begin{array}{l}\text { I feel appreciated and receive love and friendship in return for the } \\
\text { contributions that I make }\end{array}$ & 0.81 & $0.76-0.86$ & & \\
\hline Spare time & & & 0.95 & 0.96 \\
\hline My friends and relatives care about me & 0.81 & $0.76-0.86$ & & \\
\hline I adapt to my friends' and relatives' needs and demands & 0.66 & $0.56-0.74$ & & \\
\hline I feel balance and harmony in my social life and spare time & 0.80 & $0.74-0.85$ & & \\
\hline I thrive with/among my friends and relatives & 0.81 & $0.76-0.86$ & & \\
\hline I thrive with/during my spare time & 0.80 & $0.73-0.84$ & & \\
\hline I thrive in/with my friends and relatives/spare time role & 0.83 & $0.77-0.87$ & & \\
\hline I feel meaningful for/among my friends and relatives & 0.80 & $0.73-0.84$ & & \\
\hline I contribute to the development of my friends and relatives & 0.75 & $0.67-0.81$ & & \\
\hline $\begin{array}{l}\text { I feel appreciated and receive love and friendship in return for the } \\
\text { contributions that I make }\end{array}$ & 0.82 & $0.77-0.86$ & & \\
\hline Ethos & & & 0.89 & 0.90 \\
\hline I am satisfied with my work & 0.86 & $0.82-0.90$ & & \\
\hline I am satisfied with my family & 0.87 & $0.82-0.90$ & & \\
\hline I am satisfied with my housing & 0.86 & $0.82-0.89$ & & \\
\hline I am satisfied with my association with others & 0.85 & $0.81-0.89$ & & \\
\hline I am satisfied with my economy & 0.89 & $0.86-0.92$ & & \\
\hline I am satisfied with my leisure time & 0.79 & $0.72-0.84$ & & \\
\hline I am satisfied with my living habits/lifestyle & 0.83 & $0.77-0.87$ & & \\
\hline I am satisfied with my health & 0.86 & $0.81-0.89$ & & \\
\hline I am satisfied with my comprehensive circumstance of life & 0.88 & $0.85-0.91$ & & \\
\hline
\end{tabular}


ipants with a plausible interest of their health and ethos. This must be taken into consideration when the generalization of outcomes, but of less value, with regard to testing the psychometric properties of the EtWeQ questionnaire is undertaken. Further, as the questionnaire is based on self-reported information, it is possible that the participants have been hesitant to disclose sensitive data, as they may feel it is too private. This phenomenon must be reflected, but is a well-known issue in studies using patient-related outcomes measures, PROM [25]. Also, "grasping the big picture" often means a huge battery of questions and maybe 74 items seem to be in the greatest proportion. However, is quite relevant from a humanistic perspective of understanding the individual's wellness and ethos [2] [23]. A further limitation is the absence of measuring concurrent validity [21], such as; looking for the same construct at the same time. This said, due to the shortage of comprehensive questionnaires based on both philosophical and empirical grounds, this procedure was not possible.

\section{Conclusions and Implications}

The newly developed and one of the few questionnaires for "grasping the big picture" on humans, and based on both a philosophical reasoning and empirical recommendations of wellness, is shown to be a valid and reliable measurement in screening or in follow-ups of healthy people. Recommendations for future research include: replication of this study within various ethnic and age groups, but also in patients with different diagnoses. This 74-item questionnaire can provide researchers and clinicians with a standardized and inexpensive resource for computer-generated information as comprehensive individualized descriptions or as summary reports at group level in different settings for guidance in wellness and ethos improvement.

\section{References}

[1] Corbin, C.B. and Pangrazi, R.P. (2005) Toward a Uniform Definition of Wellness. Research Digest, 3, 1-8.

[2] Saylor, C. (2004) The Circle of Health: A Health Definition Model. Journal of Holistic Nursing, 22, 97-115. http://dx.doi.org/10.1177/0898010104264775

[3] Miller, G. and Foster, L.T. (2010) Critical Synthesis of Wellness Literature. Faculty of Human and Social Development, University of Victoria, Victoria.

[4] Antonovsky, A. (1979) Health, Stress and Coping. Jossey-Bass Publ., San Francisco.

[5] Antonovsky, A. (1987) Unraveling of Health-How People Manage Stress and Stay Well. Jossey-Bass Publ., San Francisco.

[6] LaRossa, R. and Reitzes, D.C. (1993) Symbolic Interactionism and Family Studies. In: Boss, P.G., Doherty, W.J., LaRossa, R., Schumm, W.R. and Steinmetz, S.K., Eds., Sourcebook of Family Theories and Methods: A Contextual Approach. Plenum, New York, 135-163. http://dx.doi.org/10.1007/978-0-387-85764-0_6

[7] Verdonk, P., de Rijk, A., Klinge, I. and de Vries, A. (2008) Sickness Absence as an Interactive Process: Gendered Experiences of Young, Highly Educated Women with Mental Health Problems. Patient Education and Counselling, 73, 300-306. http://dx.doi.org/10.1016/j.pec.2008.06.003

[8] House, J.S. (1981) Work Stress and Social Support. Addison-Wesley, Reading.

[9] Ryan, R.M. and Deci, E.L. (2000) Self-Determination Theory and the Facilitation of Intrinsic Motivation, Social Development, and Well-Being. American Psychology, 55, 68-78. http://dx.doi.org/10.1037/0003-066X.55.1.68

[10] Reiss, S. (2000) Who Am I? The 16 Basic Desires that Motivate Our Actions and Define Our Personalities. The Berkeley Publ Group, New York.

[11] Niedhammer, I., Chastang, J.F., Sultan-Taieb, H., Vermeylen, G. and Parent-Thirion, A. (2013) Psychosocial Work Factors and Sickness in 31 Countries in Europe. European Journal of Public Health, 23, 22-29. http://dx.doi.org/10.1093/eurpub/cks124

[12] Niedhammer, I., Sultan-Taieb, H., Chastang, J.F., Vermeylen, G. and Parent-Thirion, A. (2012) Exposure to Psychosocial Work Factors in European Countries. Occupational Medicine (London), 62, 196-202. http://dx.doi.org/10.1093/occmed/kqs020

[13] Sperlich, S., Arnhold-Kerri, S. and Geyer, S. (2011) What Accounts for Depressive Symptoms Among Mothers? The Impact of Socioeconomic Status, Family Structure and Psychosocial Stress. International Journal of Public Health, 56, 385-396. http://dx.doi.org/10.1007/s00038-011-0272-6

[14] Sultan-Taieb, H., Lejeune, C., Drummond, A. and Niedhammer, I. (2011) Fractions of Cardiovascular Diseases, Mental Disorders, and Musculoskeletal Disorders Attribute to Job Strain. International Archives in Occupational and Environmental Health, 84, 911-925. http://dx.doi.org/10.1007/s00420-011-0633-8 
[15] Repetti, R.L., Wang, S. and Saxbe, D.E. (2011) Adult Health in the Context of Every Family Life. Annals of Behavioral Medicine, 42, 285-293. http://dx.doi.org/10.1007/s12160-011-9293-X

[16] Dziak, E., Janzen, B.L. and Muhajarine, N. (2010) Inequalities in the Psychological Wellbeing of Employed, Single and Partnered Mothers: The Role of Psychosocial Work Quality and Work-Family Conflict. International Journal for Equity in Health, 9, 6. http://dx.doi.org/10.1186/1475-9276-9-6

[17] Norlund, S., Reuterwall, C., Höög, J., Lindahl, B., Janlert, U. and Birgander, L.S. (2010) Burnout, Working Conditions and Gender-Results from the Northern Sweden MONICA Study. BMC Public Health, 10, 326. http://dx.doi.org/10.1186/1471-2458-10-326

[18] Brown, S.C., Geiselman, P.J., Copeland, A.L., Gordon, C. and Richard-Eaglin, A. (2008) Reliability and Validity of the Personal Wellness Profile (PWP) Questionnaire in African American College Women. Journal of Cultural Diversity, 15, 163-167.

[19] Streiner, D.L. and Norman, G.R. (2008) Health Measurement Scales: A Practical Guide to Their Development and Use. Oxford University Press, New York.

[20] Kuusela, H. and Paul, P. (2000) A Comparison of Concurrent and Retrospective Verbal Protocol Analysis. American Journal of Psychology, 113, 387-404. http://dx.doi.org/10.2307/1423365

[21] Rattray, J. and Jones, M.C. (2007) Essential Elements of Questionnaire Design and Development. Journal of Clinical Nursing, 16, 234-243. http://dx.doi.org/10.1111/j.1365-2702.2006.01573.x

[22] Tappatrampet. www.tappa.se

[23] Creswell, J.W. (2013) Qualitative Enquiry and Research Design: Choosing Among Five Traditions. Sage, London.

[24] Cohen, J., Cohen, P., West, S.G. and Aiken, L. (2003) Applied Multiple Regression/Correlation Analysis for the Behavioral Science. 3rd Edition, Lawrence Erlbaum Associates, New Jersey.

[25] Magasi, S., Ryan, G., Revicki, D., Lenderking, W., Hays, R.D., Brod, M., Snyder, C., Boers, M. and Cella, D. (2012) Content Validity of Patient-Reported Outcome Measures: Perspectives from a PROMIS Meeting. Quality of Life Research, 21, 739-746. http://dx.doi.org/10.1007/s11136-011-9990-8 
Scientific Research Publishing (SCIRP) is one of the largest Open Access journal publishers. It is currently publishing more than 200 open access, online, peer-reviewed journals covering a wide range of academic disciplines. SCIRP serves the worldwide academic communities and contributes to the progress and application of science with its publication.

Other selected journals from SCIRP are listed as below. Submit your manuscript to us via either submit@scirp.org or Online Submission Portal.
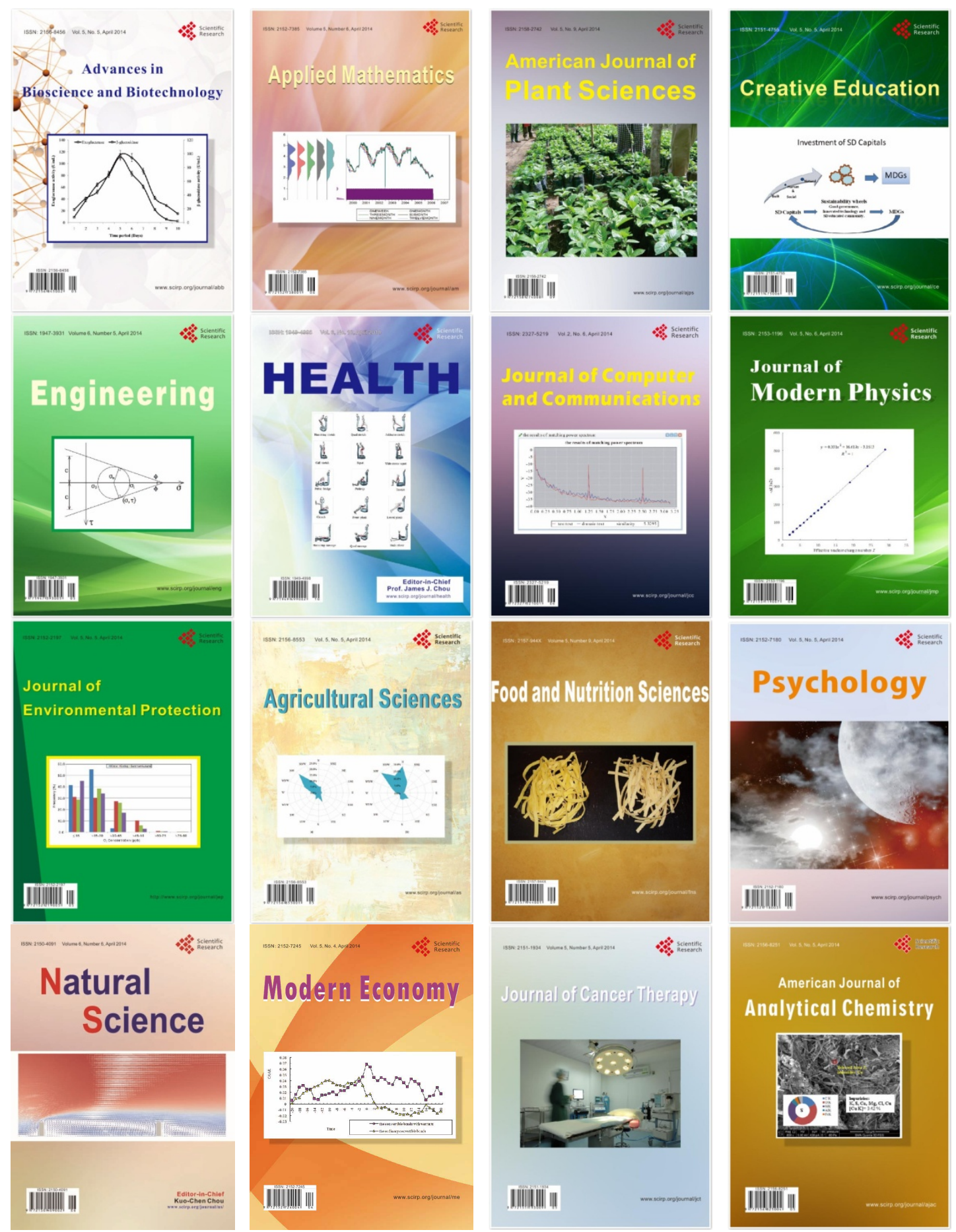